of steel only begin to obtrude itself and irritate more than three years after it became lodged at the back of the larynx?

When at Lemnos, and when I removed the piece from his brow two years later in Brisbane, he did not even complain of his throat or have any throat symptoms. Surely the irritation began when the steel rusted and the rust particles became dissolved in the surrounding tissues. When at Lemnos I asked him how he got his wounds, he told me that he was carrying up some bombs to the front trenches and that one of them burst. On my exclaiming, " It's hard lines to be injured by one of your own bombs," he replied, "Oh, I don't know-I've ' done for' a lot of Turks with those bombs." No wonder our men did so well when that was their attitude!

It appears to me that the lessons from these cases are two-fold. First, that pieces of steel near vital tissues should not be left if they can be extracted. Second, that if it proves impossible to remove a piece of steel from the fundus with a giant magnet soon after the injury, the best time, of course, a further attempt should be made when siderosis supervenes, because the onset of siderosis probably loosens the piece of steel in its bed and makes it more likely to move forward when the giant magnet is applied. The cases referred to, indeed, suggest this conclusion.

Is it not possible that a giant magnet may prove of use to remove small, otherwise inaccessible, pieces from the brain through a trephine wound?

\title{
OPHTHALMOMYIASIS
}

BY

\section{Dr. A. TICHO}

JERUSALEM

Ophthalmomyasis is the name used to describe the several symptoms caused in the eye and its annexes by the larvae of diptera. According to the place in which they are found we can distinguish (C. Behr) between an external ophthalmomyiasis when the larvae are found in the lids, lacrimal sac and conjunctiva, i.e., outside the eyeball, and an internal ophthalmomyiasis when the globe has been penetrated. The latter group may be further subdivided into an anterior and a posterior internal ophthalmomyiasis ; in the former the larvae have not penetrated beyond the anterior chamber, but have done so in the latter.

The disease is said to be common on the shores of Mexico, Peru, Chili, and, according to reports from Dr. Kuznezow and 
Dr. Goldschmidt, also in Central Asia. It is of rare occurrence in other parts of America and Africa, and very rare in Europe.

Six cases of external ophthalmomyiasis have come under my personal observation in the last ten years. In all of these cases the history was very similar. The patients all stated that something struck against the eye and was immediately followed by pain. The pain was described as severe and of a scratching or rubbing nature. In two of the cases the pain was described as not of any severity, in one case probably on account of the presence of trachoma. The suggestion that the comparative lack of pain was due to the presence of trachoma was based on my experience in schools where I found that I could remove foreign bodies such as flies, lice, wings of beetles, etc., from the conjunctiva of trachomatous children without any complaint of pain or subsequent irritation of the eye. The case in which trachoma was present only presented slight symptoms of the irritation due to a foreign body. In the other case in which pain was not severe the infection was only slight. With the exception of the trachoma case all the others showed marked oedema of the lids, conjunctival and ciliary injection, chemosis, swelling of the fornices and small haemorrhages of the conjunctiva. Follicles have been noted in these cases. but were not present in my series.

The diagnosis was made by the discovery of longish bodies of a whitish colour with a darker tail possessing worm-like movements. These bodies were situated at the limbus, in the tarsal conjunctiva and the fornix. They escaped on attempting to remove them with a Daviel spoon, but were paralysed by a drop of 5 per cent. cocain and were then easily removed. In five of the six cases the right eye was affected and the left eye only in one. I removed in one case four, in three cases three, and in two cases two bodies of about $1 \mathrm{~mm}$. long by $0.3 \mathrm{~mm}$. broad which were recognized as fly larvae. After the extraction of the larvae the pain ceased immediately and the conjunctiva returned to its normal state.

In one case reported by Betti, in which the larvae were deposited in the eye, the entrance of the nose and the throat, otitis media followed, but on the whole we can say that larvae, even when of a dangerous type, will not do much harm if removed at a sufficiently early stage. Thus in Lotin's case the larva was that of sarcophila rohlfarti, in Kaiser's that of a sarcophaga, and in Guzmann's that of lucilia sericata, yet, in spite of all of them being known as tissue destroyers, only conjunctivitis was caused.

The fact that in the cases observed by me the larvae could be retained in the conjunctival sac for two days without any destructive action seems to indicate that they have no rapid injurious effect on the human eye.

In two of my cases I was accidentally prevented from deter-. 
mining the exact nature of the insect. In two other cases the larvae were identified by I. C. Nielsen as first stage larvae of rhinoestrus purpureus de geer (also known as rhinoestrus purpureus brauer) which is said to be a frequent cause of ophthalmomyiasis in Russia and Siberia. In one case the larvae were sent by Dr. Buxton to Major W. S. Patton, of Edinburgh, who identified them as first stage larvae of oestrus ovis. The larvae in the last case were also sent to Major Patton, who has not yet reported on them. Professor Fuelleborn, who discovered the first case of ophthalmomyiasis in Northern France during the war, saw the larvae identified by Nielsen, and considers that owing to some slight differences when compared with those of rhinoestrus purpureus, they may belong to another closely related species of fly. He also thinks that the case described by Betti (identified by Betti as oestrus ovis), and that described by Kaiser (identified as sarcophaga), as also the "Thimni" disease of the eye found in Algiers and the Central Sahara, and thought by the brothers Sergent to be due to oestrus ovis, were all caused by the rhinoestrus purpureus. On the other hand, Major Patton, in his report on my larvae, says that he does not believe that rhinoestrus purpureus occurs in the human eye at all, and the previous records are due to faulty identification.

The question of the deposition of the larvae by the adult fly is, in my opinion, answered in the affirmative by the nature of the pain which begins immediately and remains of the same character. The flies of the genus sarcophaga and the tsetse fly are known to be larviparous. Betti considers that the eggs of oestrus oris ripen on the surface of the female and in the process of flying are thrown against the eye or its surroundings.

The ages of my cases were as follows: $-8,14,17,35,36,43$. Four of them occurred in the summer, one in October and one in December. In all of my cases the disease began suddenly while the patient was out of doors and awake; the first in the garden while the patient was ironing, the second while the patient was sitting under a tree, as was also the case with the sixth, the third while the patient was entering a carriage, and in the fourth the patient was also out of doors.

In dealing with ophthalmomyiasis I have only met with cases in which the symptoms pointed to conjunctivitis accompanied by the irritation of foreign bodies. In tropical countries tumour-like formations in the conjunctiva and neighbourhood of the lacrimal glands were recorded by Klyt, and in the neighbourhood of the inner canthus by Gradenigo and Gann. Lagleyze has also recorded cases of furuncle-like disease of the upper lid, and Moura and Croussard have observed infection of the lacrimal sac. Dr. Mancini, of Jerusalem, tells me that he once treated a patient with 
an abscess on the right cheek with a small fistulous opening near the lower border of the orbit. The sac, when opened, proved to be full of larvae.

The following are the records of my cases:-

CASE 1. J. K., a woman of 36 , who had not had any previous eye complaint, felt a sudden pain in the right eye while ironing in the garden. The sensation was that of the entry of a foreign body with continually increasing pain. On examination there were present slight oedema of the lids with conjunctival swelling and ciliary injection with slight chemosis. The conjunctival fornix was swollen and small conjunctival haemorrhages were present. These symptoms were confined to the right eye, the left eye being normal. Above the caruncle focal illumination showed a small foreign body resembling a flake of mucus. This, on attempted removal, was found to be adherent and, on closer observation, showed slight contractile movements. After anaesthetizing the conjunctiva the foreign body was easily detached and placed on a slide. The movements, which had stopped under the influence of cocain, then recommenced and continued as long as it was kept moist with tears or normal saline. Two more similar bodies were removed from the upper fornix. I instructed the patient to return again on the following day as, on account of the small size and transparent nature of the foreign bodies, I was not sure that I had removed all. The irritation started again in the night, and two more larvae were removed next morning. After three days' treatment with protargol and vellow oxide ointment the patient was cured. The entomological examination made at Hamburg, through the kindness of Professor Muehlens, revealed the presence of an oestrus-like larva.

CASE 2. A. B., a man of 35 , was seen on July 14,1915 . $\mathrm{He}$ stated that on the previous day while sitting under a tree he felt a slight blow on his right eye. From this eye three larvae were removed.

CASE 3. A. S., a man of 17 , was seen by me on July $15,1915$. He stated that on the previous day when entering a carriage a fly had struck his left eye causing pain that had continued. I could find only one larva. The examination was difficult on account of the presence of muco-purulent conjunctivitis (Koch-Weeks) and trachoma. The larva was lost sight of in a clot of pus. After the flake of pus had been in physiological salt solution for some hours the larva was visible and showed lively movements. J. C. Nielsen, of Copenhagen, identified, the larva as that of rhinoestrus purpureus in the first stage.

CASE 4. H. A., a girl of 14 , was seen by me on July 3,1921 . She complained of a scratching sensation in her right eye 
beginning the day before. Two days before she thought something had fallen into the eye. I found old trachoma in both eyes. In the right eye I found a small white moving body which escaped on attempted removal, but ceased to move after the application of cocain, and was then readily removed with a Daviel spoon. Four more larvae were removed in this way. Beyond small conjunctival haemorrhages the eye showed no reaction and had quite recovered after three days' treatment with yellow oxide ointment. W. J. Patton identified the larvae as first stage larvae of oestrus ovis.

CASE 5. A. M., a boy of 8 , came to me on October 23, 1921, and said that on the previous day while playing in the garden he suddenly felt severe pain in the right eye. I found that he had muco-purulent conjunctivitis (probably Koch-Weeks). I saw a larva in the upper fornix of the right eye which I removed after the use of cocain, but lost it after removal.

CASE 6. P. R., a man of 43 , consulted me on December 12 , 1922. He stated that on the previous sunny day while in his garden a fly of the size of a " wine-fly " struck the inner corner of his right eye. The pain increased by midnight, but was never very severe. I found much swelling of the upper lid of the right eye with conjunctival chemosis. At the middle of the lower margin of the cornea I found a larva fixed by its darker tail end, while the opposite end was moving. Two other larvae were found in the fornix near the lacrimal gland. These were removed after anaesthetization and placed in physiological saline. They have been sent to Mr. Patton. The conjunctiva was almost normal on the following day.

Ophthalmomyiasis of the inner eye in which the eye is the only organ containing larvae has not so far come under my observation. Six cases have been recorded as occurring in Europe. In three of these (Staehlberg, Krautner, Evetzki-Kennel) the larvae were in the anterior chamber; in the other three (Hess-Grenberg, G. Behr, v. Schmidt zu Wellenberg) in the posterior part of the eye. In the case described by Evetzki-Kennel the larvae were not identified; in the other five cases they were considered to be first stage larvae of hypoderma bovis. The patients were all under ten years of age.

In the Estrid disease in Europe the position of the larvae in the eye was the decisive factor in the result. It is astonishing how well the anterior chamber tolerated the larvae. Pain and iritis at intervals were the main symptoms, and, even after long duration of the affection the eye could be saved after removal of the larvae from the anterior chamber. On the other hand, in cases of ophthalmomyiasis interior posterior, diagnosis was impossible on account of the resulting opacity of the vitreous and the deposit on the back of the cornea. In two cases histological examination 
showed suppurative choroiditis with detached retina, and, in another exudative choroiditis.

As regards the manner in which the larvae reached the posterior part of the eye there are three possible methods; first the direct way through the cornea, which, according to Kuznezow, can be frequently observed in Central Asia; secondly, as in Schmidt zu Wellenburg's case, through the sclera (in this case reaching the sclera from the cheek), and, lastly, through the blood-vessels and lymphatics, as Hess believed occurred in his case.

Ophthalmomyiasis may also be a secondary disease, the result of skin myiasis (creeping disease) or a consequence of myiasis of the nose with larvae boring into the orbit and destroying the eyes and causing septic meningitis. It may also result from a general myiasis which may attack unconscious or drunken persons sleeping out of doors. Patients suffering from ozoena are particularly liable to attack (Schultz-Zehden).

\section{REFERENCES}

1. Behr, C.-Ueber Ophthalmomyasis interna und externa. Klin Monatsbl. $f$. Augenheilk., Vol. LXIV, 1920.

2. Fuelleborn, F.-Ueber ophthalmomyasis und einen solchen fall aus Nordfrankreich. Arch. f. Schiffs u. Tropen.-Hvgiene, Vol. XXIII, 1919. Reference in Klin. Monatsbl.f. Augenheilk., Vol. LXIII., 1919.

3. Goldschmidt, W.-Einige Bemerkungen zur Frage de Ophthalmomyasis. Weiner Klin. Wochenschr. Nr. 48, 1919; Weiner Klin. Wochenschr., Nr. 32, 1922 (Referred to by Lauber in Graefe-Saemisch Handbuch ; Die Erkrankungen des Glaskoerpers, p. 431, 1922.)

4. Patton, W. S. and Cragg, F. W.-Text Book of Medical Entomology, 1913.

5. Ticho. A. - Beitrag z. Ophthalmomyasis. Arch. f. Schiffs u. Tropen-Hygiene, 1917.

6. v. Schmidt zu Wellenburg.-Dipteren Larva als Ursache eitriger Chorioretinitis mit Netzhautabhebung. Zentralbl.f Prakt. Augenheilk., p. 41, 1917.

A further reference will be found in v. Schmidt zu Wellenburg's paper, No. 6.

\section{ANNOTATIONS}

\section{Ophthalmia Neonatorum in the Metropolitan Area}

The following figures have been issued as the statistics for ophthalmia neonatorum in the Metropolitan area, together with the numbers admitted to St. Margaret's Hospital for Ophthalmia Neonatorum under the Metropolitan Asylums Board:-

\begin{tabular}{crrrr} 
Year. & \multicolumn{2}{c}{$\begin{array}{c}\text { Cases of ophthalmia neonatorum } \\
\text { notified in the Metropolitan area. }\end{array}$} \\
$\begin{array}{c}\text { St. Margaret's Hospital } \\
\text { for ophthalmia neonatorum. }\end{array}$ \\
1919 & $\ldots$ & 870 & $\ldots$ & 281 \\
1920 & $\ldots$ & 1186 & $\ldots$ & 252 \\
1921 & $\ldots$ & 1076 & $\ldots$ & 213 \\
1922 & $\ldots$ & $\ldots 66$ & $\ldots$ & 213
\end{tabular}

